Pacific Journal of Mathematics

COMPARISON THEOREMS FOR ELLIPTIC DIFFERENTIAL 


\title{
COMPARISON THEOREMS FOR ELLIPTIC DIFFERENTIAL SYSTEMS
}

\author{
C. A. SWANSON
}

\begin{abstract}
Comparison theorems of Sturm's type are established for systems of quasilinear elliptic partial differential equations. Specialization to ordinary linear systems and to single partial differential inequalities yields sharper results than those previously available.
\end{abstract}

The classical Sturm-Picone comparison theorem was generalized to systems of ordinary linear second order equations by M. Morse in 1930 [11]. Refinements and extensions of Morse's theorem have been developed by Atkinson [2], Birkhoff and Hestenes [3], Coppel [4], Diaz and McLaughlin [5], Jakubovič [7], and Lidskii [10].

A Sturmian comparison theorem for systems of linear elliptic partial differential equations was obtained by Kuks [9] in 1962, generalizing results of Picone [12] and Hartman and Wintner [6] for a single elliptic equation. The purpose here is to extend Kuks' result to quasilinear elliptic systems and to sharpen the original theorem. In particular, a "strong" comparison theorem of Kreith's type [8] is proved for arbitrary regular bounded domains by means of a device used by Allegretto [1] for single equations. An alternative procedure depending on Hopf's maximum principle, as employed by Kreith [8] and the author [13], could have been used to obtain the same conclusion under stronger regularity assumptions on the boundary.

The hypothesis used by Kuks, Morse, and others that the coefficients of the differential operators satisfy certain pointwise inequalities is replaced by a weaker integral inequality. In particular, specialization of our result to one dimension yields a refinement of Morse's theorem.

Let $G$ be a nonempty regular bounded domain in $n$-dimensional Euclidean space $R^{n}$ and let $H$ be a domain in $R^{m}$ containing the origin, $m, n=1,2, \cdots$. Points in $R^{n}$ will be denoted by $x=\left(x_{1}, x_{2}, \cdots, x_{n}\right)$ and differentiation with respect to $x_{i}$ by $D_{i}, i=1,2, \cdots, n$. The quasilinear elliptic partial differential operator $l$ defined by

$$
l u=\sum_{i, j=1}^{n} D_{i}\left[a_{i j}(x, u) D_{j} u\right]+b(x, u) u, \quad a_{i j}=a_{j i}
$$

will be considered for $x \in G, u \in H$, where $b$ and each $a_{i j}$ are real symmetric $m \times m$ matrix functions of class $C^{1}(\bar{G} \times H)$, and the $m n \times m n$ matrix $\left(a_{i j}(x, u)\right)(i, j=1,2, \cdots, n)$ is positive definite in $G \times H$. The domain $\mathfrak{D}$ of $l$ is defined as the set of all vector func- 
tions $u \in C^{2}(G) \cap C^{1}(\bar{G})$ with range in $H$.

The notation $\mathfrak{D}^{m}$ will be used for the set of all $m \times m$ matrix functions whose column vectors $v_{i} \in \mathfrak{D}, i=1,2, \cdots, m$. The conclusion of the comparison theorems below concerns matrices $V \in \mathfrak{D}^{m}$ with the property that $V^{T} L V$ is negative semidefinite throughout $G$, where $L$ is the partial differential operator defined by

$$
L V=\sum_{i, j=1}^{n} D_{i}\left[A_{i j}(x, V) D_{j} V\right]+B(x, V) V, A_{i i}=A_{j i} .
$$

It is assumed that $B$ and each $A_{i j}$ are real symmetric $m \times m$ matrix functions of class $C^{1}\left(\bar{G} \times H^{m}\right)$ and that the $m n \times m n$ matrix $\left(A_{i j}(x, V)\right)$ is positive definite in $G \times H^{m}$.

Let $f[u], F[u, v]$ be the functionals defined by

$$
\begin{gathered}
f[u]=\int_{G}\left[\sum_{i, j} D_{i} u^{T} a_{i j}(x, u(x)) D_{j} u-u^{T} b(x, u(x)) u\right] d x \\
F[u, V]=\int_{G}\left[\sum_{i, j} D_{i} u^{T} A_{i j}(x, V(x)) D_{j} u-u^{T} B(x, V(x)) u\right] d x
\end{gathered}
$$

with domains $\mathfrak{D}_{f}, \mathfrak{D}_{f} \times \mathfrak{D}^{m}$, respectively, where $\mathfrak{D}_{f}$ denotes the set of all vector functions $u \in C^{1}(\bar{G})$ with range in $H$ such that $u$ vanishes identically on $\partial G$.

In analogy with Morse's definition of a conjugate basis for an ordinary linear system [11, p. 56], a matrix $V$ is said to be conjugate relative to $L$ if and only if $Y_{i}(x, V)=0$ identically for $i=1,2, \cdots, n$, where

$$
Y_{i}(x, V)=\sum_{j=1}^{n}\left[V^{T} A_{i j}(x, V) D_{j} V-\left(D_{j} V^{T}\right) A_{i j}(x, V) V\right] .
$$

Similarly to the well known fact for ordinary linear systems, it follows easily from the symmetry of the matrices involved that

$$
\sum_{i=1}^{n} D_{i} Y_{i}(x, V)=0
$$

identically in $G$ for any solution $V \in \mathfrak{D}^{m}$ of $L V=0$. As in the ordinary case, this motivates the definition of a conjugate matrix.

The first comparison theorem is "weak" in the sense that the conclusion applies to $\bar{G}$ rather than $G$. The rather simple proof of the weak theorem suggests the proof of the strong Theorem 2. For the weak theorem, $\partial G$ is required only to be piecewise $C^{1}$.

THEOREM 1. If

(i) There exists a nontrivial vector function $u \in \mathfrak{D}_{f}$ such that $f[u] \leqq 0$; 
(ii) $V \in \mathfrak{D}^{m}$ is a conjugate matrix such that $V^{T} L V$ is negative semidefinite throughout $G$; and

(iii) $f[u] \geqq F[u, V]$,

then $\operatorname{det} V(x)$ must vanish at some point in $\bar{G}$.

Proof. Suppose to the contrary that $V(x)$ is nonsingular for all $x \in \bar{G}$. Then there exists a unique $w \in \mathfrak{D}_{f}$ satisfying $u(x)=V(x) w(x)$ identically in $\bar{G}$. An easy calculation similar to that given in $[14, p$. 188] yields the following identity:

$$
\sum_{i, j}\left(V D_{i} w\right)^{T} A_{i j}(x, V) V D_{j} w+\sum_{i} D_{i}\left[(V w)^{T} \sum_{j} A_{i j}(x, V)\left(D_{j} V\right) w\right]
$$

$$
\begin{aligned}
= & \sum_{i, j} D_{i}(V w)^{T} A_{i j}(x, V) D_{j}(V w)-(V w)^{T} B(x, V) V w \\
& +(V w)^{T}(L V) w+\sum_{i} w^{T} Y_{i}(x, V) D_{i} w
\end{aligned}
$$

where $Y_{i}(x, V)$ is given by (3). Since $Y_{i}(x, V)=0$ identically for $i=1,2, \cdots, n, V^{T} L V \leqq 0$ in $G$, and $w=0$ on $\partial G$, integration of (4) over $G$ and use of Green's identity gives the inequality

$$
F[u, V] \geqq 0,
$$

where $F$ is given by (2), equality if and only if $D_{i} w=0$ identically in $G$ for each $i=1,2, \cdots, n$ and $L V \equiv 0$, i.e., $u(x)=V(x) w(x)=V(x) c$ for some constant vector $c$ and $L V \equiv 0$. However, $u=0$ on $\partial G$ and $c \neq 0$ since $u(x)$ is nontrivial by hypothesis, and hence equality in (5) implies that $V(x)$ is singular on $\partial G$. Thus the assumption that $V(x)$ is nonsingular throughout $\bar{G}$ leads to the contradiction

$$
f[u] \geqq F[u, V]>0 .
$$

Theorem 2 (strong comparison theorem). Under the hypotheses of Theorem 1 (where $\partial G \in C^{1}$ ) either det $V(x)$ vanishes at some point in $G$ or there exists a constant vector $c \neq 0$ such that $u(x)=V(x) c$ throughout $\bar{G}$.

Proof. If det $V(x) \neq 0$ in $G$, there exists a unique $w \in C^{1}(G)$ such that $u(x)=V(x) w(x)$ for all $x \in G$. Since $\partial G$ is of class $C^{1}$, it is well known that $u$ belongs to the Sobolev space $H_{0}^{1}(G)$ (the closure in the norm $\|\cdot\|_{1}$ defined by

$$
\|u\|_{1}^{2}=\int_{G}|u|^{2} d x+\sum_{i=1}^{n} \int_{G}\left|D_{i} u\right|^{2} d x
$$

of the class $C_{0}^{\infty}(G)$ of infinitely differentiable vector functions with compact support in $G$.)

Let $\left\{u_{n}\right\}$ denote a sequence of $C_{0}^{\infty}(G)$ functions converging to $u$ in 
the norm (6). It follows analogously to (5) that

$$
F\left[u_{n}, V\right] \geqq \int_{G} \sum_{i, j}\left(V D_{i} w_{n}\right)^{T} A_{i j}(x, V) V D_{j} w_{n} d x \geqq 0
$$

where $w_{n}$ is the unique solution of $u_{n}(x)=V(x) w_{n}(x), x \in G$. Since $A_{i j}(x, V(x))(i, j=1,2, \cdots, n)$ and $B(x, V(x))$ are uniformly bounded in $G$, use of (2) shows that there is a constant $K>0$ such that

$$
\begin{aligned}
\mid F\left[u_{n}, V\right] & -F[u, V] \mid \\
& \leqq K \int_{G}\left|\sum_{i, j} D_{i} u_{n}^{T} D_{j}\left(u_{n}-u\right)+D_{i}\left(u_{n}^{T}-u^{T}\right) D_{j} u\right| d x \\
& +K \int_{G}\left|u_{n}^{T}\left(u_{n}-u\right)+\left(u_{n}^{T}-u^{T}\right) u\right| d x .
\end{aligned}
$$

Application of the Schwarz inequality then yields the estimate

$$
\left|F\left[u_{n}, V\right]-F[u, V]\right| \leqq K\left(n^{2}+1\right)\left(\left\|u_{n}\right\|_{1}+\|u\|_{1}\right)\left\|u_{n}-u\right\|_{1} .
$$

Since $\lim \left\|u_{n}-u\right\|_{1}=0 \quad(n \rightarrow \infty), F[u, V] \geqq 0$ in view of (7). If $F[u, V]>0$, we obtain the contradiction $f[u]>0$ as in Theorem 1 , and hence $F[u, V]=0$.

Let $S$ denote a ball with $\bar{S} \subset G$ and define

$$
H_{S}\left[u_{n}, V\right]=\int_{S} \sum_{i, j}\left(V D_{i} w_{n}\right)^{T} A_{i j}(x, V) V D_{j} w_{n} d x .
$$

Then (7) implies that

$$
0 \leqq H_{S}\left[u_{n}, V\right] \leqq F\left[u_{n}, V\right],
$$

and the following analogue of (8) is valid:

$$
\left|H_{S}\left[u_{n}, V\right]-H_{S}[u, V]\right| \leqq M\left(\left\|w_{n}\right\|_{1, S}+\|w\|_{1, S}\right)\left\|w_{n}-w\right\|_{1, S}
$$

where $M$ is a positive constant and the subscript $S$ indicates that the integrals involved in the norm (6) are taken over $S$ only. Since $V^{-1}(x) \in C^{1}(\bar{S})$ and $w=V^{-1} u, w_{n}=V^{-1} u_{n}$, it follows that

$$
H_{S}\left[u_{n}, V\right] \rightarrow H_{S}[u, V] \text { as }\left\|u_{n}-u\right\|_{1} \rightarrow 0 .
$$

Since $F\left[u_{n}, V\right] \rightarrow F[u, V]=0$ from (8), we conclude from (9) that $H_{S}[u, V]=0$, and hence that $D_{i} w=0$ identically in $S$ for $i=$ $1,2, \cdots, n$. Since $S$ is arbitrary, $w(x)=c$ or $u(x)=V(x) c$ throughout $G$, and hence throughout $\bar{G}$ by continuity, for some nonzero constant vector $c$. This completes the proof of Theorem 2 .

It follows from Green's formula that hypothesis (i) of Theorem 1 or 2 is implied by the existence of a solution $u \in \mathfrak{D}$ of the differential inequality $u^{T} l u \geqq 0$ in $G$ such that $u=0$ on $\partial G$.

Also, hypothesis (iii) is implied by the conditions that the matrices 


$$
\left[a_{i j}(x, u(x))-A_{i j}(x, V(x))\right], B(x, V(x))-b(x, u(x))
$$

of order $m n$ and $m$, respectively, are positive semidefinite for all $x \in G$. In the linear case, hypothesis (iii) reduces to $E[u] \geqq 0$, where

$$
E[u]=\int_{G}\left[\sum_{i, j} D_{i} u^{T}\left[a_{i j}(x)-A_{i j}(x)\right] D_{j} u+u^{T}[B(x)-b(x)] u\right] d x,
$$

which is independent of $V$. The following special case of Theorem 2 is then immediate.

THEOREM 3. (Linear case). If there exists a nontrivial solution $u \in \mathfrak{D}$ of $u^{T} l u \geqq 0$ in $G$ such that $u=0$ on $\partial G$ and $E[u] \geqq 0$, then every conjugate matrix $V$ for which $V^{T} L V$ is negative semidefinite in $G$ is singular at some point in $G$ unless $u(x)=V(x) c$ for a constant vector $c \neq 0$.

This sharpens Kuks' theorem [9] in two directions: (i) Theorem 3 is "strong" in the sense described above; and (ii) The integral inequality $E[u] \geqq 0$ is weaker than Kuks' pointwise inequalities $\left[a_{i j}(x)\right] \geqq\left[A_{i j}(x)\right]$ and $B(x) \geqq b(x)$ (as forms) throughout $G$, as shown by an example in [14, p. 189] in the case $m=1$. (Since the statement of Kuks' theorem does not include the alternative $u(x)=V(x) c$, it is false as stated for (open) domains.)

In the case $m=1$, Theorem 3 extends results of Kreith [8] and Diaz and McLaughlin [5] to arbitrary regular bounded domains $G$ and to differential inequalities. In the case that $n=1$ and the hypotheses are strengthened to $l u=0$ identically in an interval $\left(x_{1}, x_{2}\right), L V=0$ in $\left(x_{1}, x_{2}\right)$, and $a(x)-A(x)$ and $B(x)-b(x)$ are positive semidefinite at every point, Theorem 3 reduces to a result of Morse [11], also stated by Diaz and McLaughlin [5] in a different form.

\section{REFERENCES}

1. W. Allegretto, A comparison theorem for nonlinear elliptic operators, (submitted for publication)

2. F.V. Atkinson, Discrete and continuous boundary problems, Academic Press, New York, 1964.

3. G.D. Birkhoff and M.R. Hestenes, Natural isoperimetric conditions in the calculus of variations, Duke Math. J. 1 (1935), 198-286.

4. W.A. Coppel, Comparison theorems for canonical systems of differential equations, J. Math. Anal. Appl. 12 (1965), 306-315.

5. J.B. Diaz and J.R. McLaughlin, Sturm comparison theorems for ordinary and partial differential equations, Bull. Amer. Math. Soc. 75 (1969), 335-339.

6. Philip Hartman and Aurel Wintner, On a comparison theorem for self-adjoint partial differential equations of elliptic type, Proc. Amer. Math. Soc. 6 (1955), 862-865. 7. V.A. Jakubovič, Oscillatory properties of solutions of canonical equations (Russian), Mat. Sb. (98) 56 (1962), 3-42. 
8. Kurt Kreith, A remark on a comparison theorem of Swanson, Proc. Amer. Math. Soc. 20 (1969), 549-550.

9. L.M. Kuks, Sturm's theorem and oscillation of solutions of strongly elliptic systems, Soviet Math. Dokl. 3 (1962), 24-27.

10. V.B. Lidskii, Oscillation theorems for canonical systems of differential equations (Russian), Dokl. Akad. Nauk SSSR 102 (1955), 877-880.

11. M. Morse, A generalization of the Sturm separation and comparison theorems in n-space, Math. Ann. 103 (1930), 52-69.

12. Mauro Picone, Un teorema sulle soluzioni delle equazioni lineari ellittiche autoaggiunte alle derivate parziali del secondo-ordine, Rend. Acc. Lincei (1) 20 (1911), 213-219. 13. C.A. Swanson, Comparison theorems for quasilinear elliptic differential inequalities, J. of Differential Equations (to appear)

14. Comparison and oscillation theory of linear differential equations, Mathematics in Science and Engineering, Volume 48, Academic Press, New York, 1968.

Received July 14, 1969. Research sponsored by the Air Force Office of Scientific Research, Office of Aerospace Research, United States Air Force, under AFOSR Grant Nr. AFOSR-69-1791.

The University of British Columbia

VANCOUver, B.C., Canada 


\section{PACIFIC JOURNAL OF MATHEMATICS}

\section{EDITORS}

H. SAMelson

Stanford University

Stanford, California 94305

\section{Richard PIERCE}

University of Washington

Seattle, Washington 98105
J. DugundjI

Department of Mathematics

University of Southern California

Los Angeles, California 90007

BASIL GoRDON*

University of California

Los Angeles, California 90024

\section{ASSOCIATE EDITORS}
E. F. BECKENBACH
B. H. NeumanN
F. WOLE
K. YosHIDA

\section{SUPPORTING INSTITUTIONS}

UNIVERSITY OF BRITISH COLUMBIA

CALIFORNIA INSTITUTE OF TECHNOLOGY

UNIVERSITY OF CALIFORNIA

MONTANA STATE UNIVERSITY

UNIVERSITY OF NEVADA

NEW MEXICO STATE UNIVERSITY

OREGON STATE UNIVERSITY

UNIVERSITY OF OREGON

OSAKA UNIVERSITY

UNIVERSITY OF SOUTHERN CALIFORNIA

\author{
STANFORD UNIVERSITY \\ UNIVERSITY OF TOKYO \\ UNIVERSITY OF UTAH \\ WASHINGTON STATE UNIVERSITY \\ UNIVERSITY OF WASHINGTON \\ * * * * \\ AMERICAN MATHEMATICAL SOCIETY \\ CHEVRON RESEARCH CORPORATION \\ TRW SYSTEMS \\ NAVAL WEAPONS CENTER
}

The Supporting Institutions listed above contribute to the cost of publication of this Journal, but they are not owners or publishers and have no responsibility for its content or policies.

Mathematical papers intended for publication in the Pacific Journal of Mathematics should be in typed form or offset-reproduced, (not dittoed), double spaced with large margins. Underline Greek letters in red, German in green, and script in blue. The first paragraph or two must be capable of being used separately as a synopsis of the entire paper. The editorial "we" must not be used in the synopsis, and items of the bibliography should not be cited there unless absolutely necessary, in which case they must be identified by author and Journal, rather than by item number. Manuscripts, in duplicate if possible, may be sent to any one of the four editors. Please classify according to the scheme of Math. Rev. 36, 1539-1546. All other communications to the editors should be addressed to the managing editor, Richard Arens, University of California, Los Angeles, California, 90024.

50 reprints are provided free for each article; additional copies may be obtained at cost in multiples of 50 .

The Pacific Journal of Mathematics is published monthly. Effective with Volume 16 the price per volume (3 numbers) is $\$ 8.00$; single issues, $\$ 3.00$. Special price for current issues to individual faculty members of supporting institutions and to individual members of the American Mathematical Society: $\$ 4.00$ per volume; single issues $\$ 1.50$. Back numbers are available.

Subscriptions, orders for back numbers, and changes of address should be sent to Pacific Journal of Mathematics, 103 Highland Boulevard, Berkeley, California, 94708.

PUBLISHED BY PACIFIC JOURNAL OF MATHEMATICS, A NON-PROFIT CORPORATION

Printed at Kokusai Bunken Insatsusha (International Academic Printing Co., Ltd.), 7-17, Fujimi 2-chome, Chiyoda-ku, Tokyo, Japan.

* Acting Managing Editor. 


\section{Pacific Journal of Mathematics}

\section{Vol. 33, No. $2 \quad$ April, 1970}

Raymond Balbes and Alfred Horn, Projective distributive lattices ....... 273

John Findley Berglund, On extending almost periodic functions ......... 281

Günter Krause, Admissible modules and a characterization of reduced left

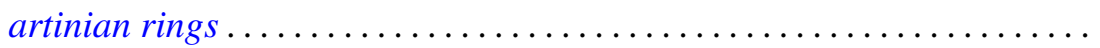

Edward Milton Landesman and Alan Cecil Lazer, Linear eigenvalues and a nonlinear boundary value problem ....................... 311

Anthony To-Ming Lau, Extremely amenable algebras ............... 329

Aldo Joram Lazar, Sections and subsets of simplexes .............. 337

Vincent Mancuso, Mesocompactness and related properties ............. 345

Edwin Leroy Marsden, Jr., The commutator and solvability in a generalized orthomodular lattice .................................. 357

Shozo Matsuura, Bergman kernel functions and the three types of canonical domains.......................................... 363

S. Mukhoti, Theorems on Cesàro summability of series .............. 385

Ngô Van Quê, Classes de Chern et théorème de Gauss-Bonnet ........... 393

Ralph Tyrrell Rockafellar, Generalized Hamiltonian equations for convex problems of Lagrange ................................ 411

Ken iti Sato, On dispersive operators in Banach lattices ............. 429

Charles Andrew Swanson, Comparison theorems for elliptic differential

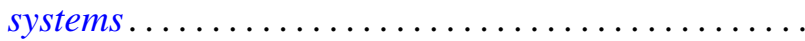

John Griggs Thompson, Nonsolvable finite groups all of whose local subgroups are solvable. II

David J. Winter, Cartan subalgebras of a Lie algebra and its ideals ... 